Proc. Indian Acad. Sci. (Chem. Sci.), Vol. 96, No. 5, March 1986, pp. 383-388.

(C) Printed in India.

\title{
Magnetic susceptibility studies of lead oxyhalide glasses containing transition metal oxides $†$
}

\author{
B G RAO, N Y VASANTHACHARYA and K J RAO* \\ Solid State and Structural Chemistry Unit, Indian Institute of Science, Bangalore 560012 , \\ India
}

MS received 23 August 1985; revised 13 December 1985

\begin{abstract}
Magnetic susceptibility studies of lead oxyhalide glasses containing high concentrations of transition metal oxides such as $\mathrm{MnO}$ and $\mathrm{Fe}_{2} \mathrm{O}_{3}$ have been performed. While they exhibit predominantly antiferromagnetic interactions, the low temperature $(<100 \mathrm{~K})$ region is dominated by paramagnetic contributions. The behaviour in these glasses is found to be similar to that of covalent oxide glasses and is different from that of purely ionic sulphate glasses.
\end{abstract}

Key words. Magnetic susceptibility; oxyhalide glasses; transition metal oxides.

\section{Introduction}

Lead oxyhalide glasses in the systems, $\mathrm{PbO}-\mathrm{PbF}_{2}$ and $\mathrm{PbO}-\mathrm{PbCl}_{2}$ can be prepared with high concentrations of transition metal (TM) ions such as $\mathrm{Fe}_{2} \mathrm{O}_{3}$ and $\mathrm{MnO}$ (RaO and Rao 1985a). We have earlier investigated these glasses containing TM ions by ESR and optical spectroscopies (Rao and Rao 1985a, 1985b). It was found that $\mathrm{Fe}^{3+}$ ions prefer non-substitutional 4-coordinated sites of their own whereas $\mathrm{Mn}^{2+}$ ions acquire a slightly distorted octahedral coordination of the type, $\left[\mathrm{MnO}_{2} X_{4}\right],(X=\mathrm{F}, \mathrm{Cl})$ similar to the sites of $\mathrm{Pb}^{2+}$ ions in these glasses (Rao and Rao 1984; Rao et al 1984a, 1984b). It was also found that part of the added $\mathrm{Mn}^{2+}$ ions gets oxidized to $\mathrm{Mn}^{3+}$ state during glass preparation. In glasses containing high concentrations of $\mathrm{Fe}_{2} \mathrm{O}_{3}$ or $\mathrm{MnO}$, magnetic interaction between rM ions is dominantly dipolar. But even then we observed (Rao and Rao 1985a) that a significant fraction of $\mathrm{Fe}^{3+}$ and $\mathrm{Mn}^{2+}$ ions are present in magnetically isolated sites.

We therefore consider that a study of the temperature dependence of magnetic susceptibilities is in order, since it provides information about the nature of the interaction between the TM ions. Additionally the curie constants evaluated from susceptibility measurements give information about the valence state of the TM ions. Further, the influence of non-magnetic (lead oxyhalide) host glass in which the ionicity of bonding increases with halide concentration is also worth investigating, because in purely ionic sulphate glasses the interaction between TM ions was found to be weakly ferromagnetic (Rao and Sundar 1981), whereas in most (covalent) oxide glasses the interaction was found to be antiferromagnetic (Shinkel and Rathenau 1965; Simpson and Lucas 1971; Hasegawa 1971; Egami et al 1972,1973; Wilson et al 1973; Friebele and Koon 1974; Burzo et al 1982).

† Communication No. 324 from the Solid State and Structural Chemistry Unit.

* To whom all correspondence should be addressed. 
In this short communication we present the results of our magnetic susceptibility studies of lead oxyhalide glasses containing high concentrations of $\mathrm{MnO}$ and $\mathrm{Fe}_{2} \mathrm{O}_{3}$. Our results suggest that the nature of interaction in these glasses is dominantly antiferromagnetic. We have discussed the possible origin of this effect.

\section{Experimental}

$\mathrm{PbO}-\mathrm{PbF}_{2}$ and $\mathrm{PbO}-\mathrm{PbCl}_{2}$ glasses containing various quantities of $\mathrm{Fe}_{2} \mathrm{O}_{3}$ and $\mathrm{MnO}$ were prepared by the procedure reported earlier (Rao and Rao 1985a). In this method, melts of appropriate composition containing 5 to $10 \mathrm{~mol} \%$ of $\mathrm{Fe}_{2} \mathrm{O}_{3}$ or $\mathrm{MnO}$ (added as $\mathrm{MnC}_{2} \mathrm{O}_{4}$ which decomposes to $\mathrm{MnO}$ ) were quenched into thin disks between two steel plates. The glasses so prepared were found to be homogeneous and no phase separation was noticed.

Magnetic susceptibility of these glasses in the temperature region of $15-300 \mathrm{~K}$ was measured by the Faraday method using a Cahn RG vacuum recording electrobalance. Specially shaped pole pieces are used for generating a constant field gradient. The maximum field used was around $4000 \mathrm{G}$. $\mathrm{Hg}\left[\mathrm{Co}(\mathrm{NCS})_{4}\right]$ was used as calibrant. A closed cycle helium cryostat (model cs 202) manufactured by Air Products Inc., usA, was used for low temperature measurements. The molar magnetic susceptibilities reported here are corrected for diamagnetic contributions of the constituent ions in the glasses.

\section{Results and discussion}

Temperature variation of the inverse molar magnetic susceptibility, $\chi_{M}^{-1}$, for various glasses containing different concentrations of $\mathrm{Fe}_{2} \mathrm{O}_{3}$ is shown in figure 1. Similar $\chi_{M}^{-1}$ vs $T$ plots for glasses with different concentrations of $\mathrm{MnO}$ are presented in figure 2.

The temperature variations of the inverse susceptibilities exhibit the following interesting features: (1) There appears to be two linear temperature regions, one below $100 \mathrm{~K}$ (low temperature, $\mathrm{LT}$ region) and the other above $100 \mathrm{~K}$ (high temperature, HT region) in all glasses though this is only weakly apparent in $\mathrm{MnO}$-containing glasses; (2) the susceptibility increases by almost an order of magnitude for a two-fold increase of $\mathrm{Fe}_{2} \mathrm{O}_{3}$ concentration while the increase is almost proportional to the concentration in the case of $\mathrm{MnO}$; (3) the susceptibility increases enormously for heat treated glasses containing $0.5 \mathrm{~mol} \%$ of $\mathrm{Fe}_{2} \mathrm{O}_{3}$. When the glass was heated above its crystallization temperature ( $\simeq 600 \mathrm{~K}$ ) for 2 hours; (4) the LT and HT regions in $\mathrm{MnO}$ doped glasses possess considerably smaller differences in slopes as compared to $\mathrm{Fe}_{2} \mathrm{O}_{3}$-doped glasses, in fact, $\mathrm{Fe}_{2} \mathrm{O}_{3}$-doped glasses exhibit distinctly large curvature in the region of $100 \mathrm{~K}$, (5) the slope of the HT region of glass containing a higher concentration of $\mathrm{MnO}$ is lower than the corresponding slope in the glass containing lower concentration.

The two linear regions were visually identified and were least square fitted. The temperature variation of $\chi_{M}^{-1}$ in the two regions may be described by the Curie-Weiss law,

$$
\chi_{M}=C /\left(T+\theta_{p}\right)
$$

where $C$ is the Curie constant and $\theta_{p}$ is an effective Curie temperature. Effective 


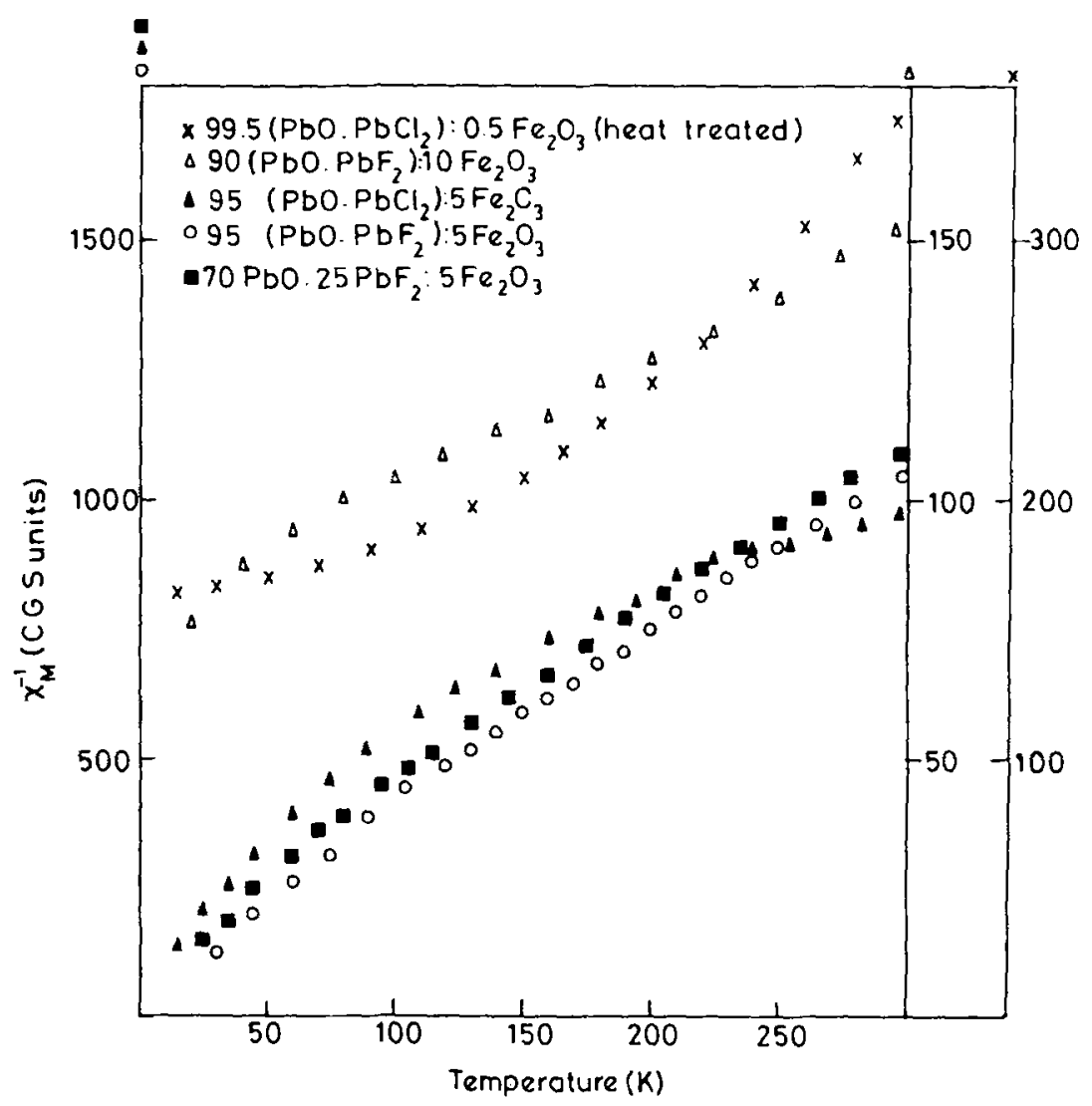

Figure 1. Temperature variation of inverse magnetic susceptibility for various glasses containing $\mathrm{Fe}_{2} \mathrm{O}_{3}$. The $y$-axes for different curves in the figure are identified by the symbols at the top.

magnetic moment, $\mu_{\text {eff }}$ can be calculated from $\chi_{M}$ by the following formula

$$
\mu_{\text {eff }}=2 \cdot 83(C / x)^{1 / 2}
$$

where $x$ is the mole fraction of the transition metal ions in the glass. The calculated values of $\theta_{p}$ and $\mu_{\text {efr }}$ are given in table 1 . The values of $\theta_{p}$ for the high temperature regions in all cases suggest that interactions are predominantly antiferromagnetic in these glasses. It may also be noted that glasses containing $\mathrm{Fe}_{2} \mathrm{O}_{3}$ give rise to larger $\boldsymbol{\theta}_{p}$ values as compared to glasses containing $\mathrm{MnO}$. Further, $\theta_{p}$ is higher for glasses with higher concentration of $\mathrm{TM}$ ions in the case of $\mathrm{Fe}_{2} \mathrm{O}_{3}$ whereas it is lower in the case of $\mathrm{MnO}$. The magnitudes of $\theta_{p}$ suggest that the manganese ions are weakly coupled in the glass matrices in comparison to $\mathrm{Fe}^{3+}$ ions which are quite strongly coupled. This is quite in keeping with the structural features of these glasses in that the substitutional octahedral positions taken up by $\mathrm{Mn}^{2+} / \mathrm{Mn}^{3+}$ ions are spatially separated by larger distances than the tetrahedral positions preferred by $\mathrm{Fe}^{3+}$ ions. The spatial closeness of $\mathrm{Fe}^{3+}$ positions in these glasses is likely to be due to the tendency of $\mathrm{Fe}^{3+}$ ions to cluster together (Bandyopadhyay et al 1980). This clustering attains its limits when the glass is 


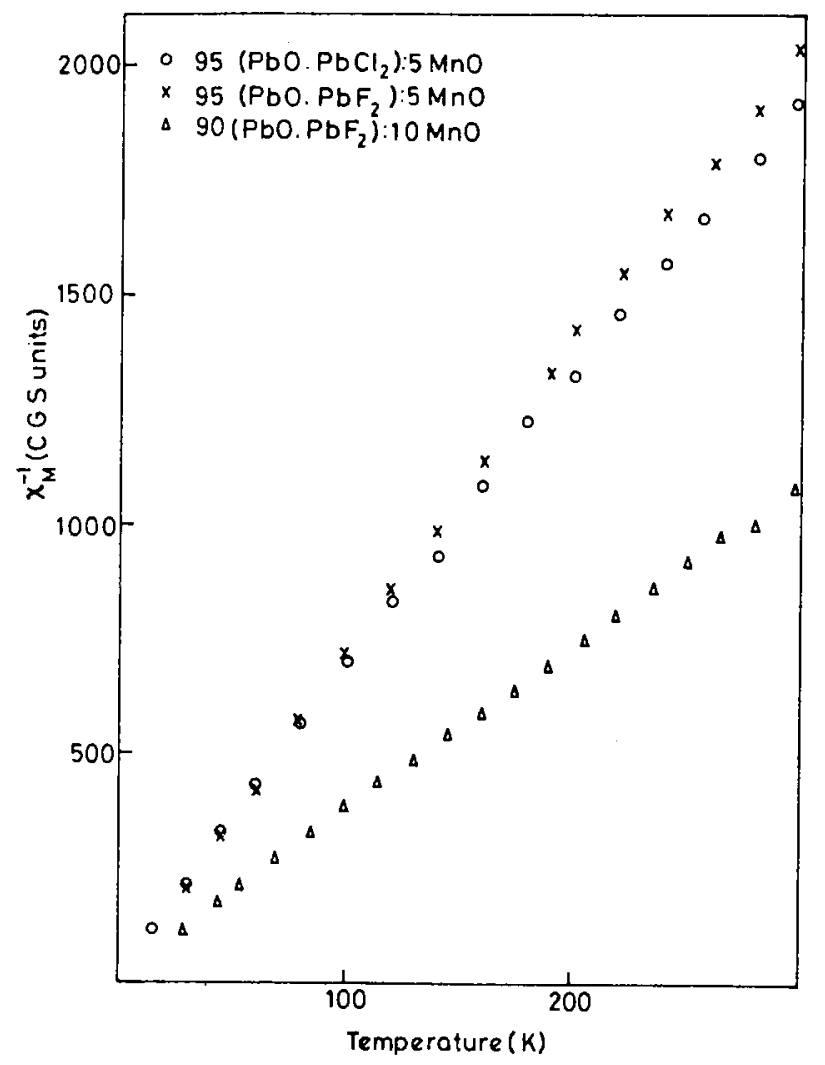

Figure 2. Temperature variation of inverse susceptibilities of various glasses containing MnO.

Table 1. Values of $\theta_{p}$ and $\mu_{\text {eff }}$ obtained from the high temperature (HT) region and $\theta_{p}$ values obtained from the low temperature (LT) region.

\begin{tabular}{|c|c|c|c|c|}
\hline \multirow[b]{2}{*}{ No. } & \multirow[b]{2}{*}{ Glass composition } & \multirow{2}{*}{$\begin{array}{c}\text { LT region } \\
\theta_{p}\end{array}$} & \multicolumn{2}{|c|}{ HT region } \\
\hline & & & $\theta_{p}$ & $\mu_{\text {eff }}$ \\
\hline 1. & 47.5 $\mathrm{PbO}: 47.5 \mathrm{PbCl}_{2}: 5 \mathrm{MnO}$ & 1.9 & $4 \cdot 6$ & 4.93 \\
\hline 2. & $47 \cdot 5 \mathrm{PbO}: 47.5 \mathrm{PbF}_{2}: 5 \mathrm{MnO}$ & 1.9 & $9 \cdot 3$ & 4.92 \\
\hline 3. & $450 \mathrm{PbO}: 450 \mathrm{PbF}_{2}: 10 \mathrm{MnO}$ & $0-9$ & 5.9 & $4 \cdot 72$ \\
\hline 4. & $47.5 \mathrm{PbO}: 47.5 \mathrm{PbCl}_{2}: 5 \mathrm{Fe}_{2} \mathrm{O}_{3}$ & $12 \cdot 0$ & 116.4 & 7.84 \\
\hline 5. & 47.5 $\mathrm{PbO}: 47.5 \mathrm{PbF}_{2}: 5 \mathrm{Fe}_{2} \mathrm{O}_{3}$ & $2 \cdot 6$ & $35 \cdot 0$ & 5.04 \\
\hline 6. & $70 \mathrm{PbO}: 25 \mathrm{PbF}_{2}: 5 \mathrm{Fe}_{2} \mathrm{O}_{3}$ & 9.5 & $45 \cdot 3$ & 4.99 \\
\hline 7. & 45.0 PbO: $45 \cdot 0 \mathrm{PbF}_{2}: 10 \mathrm{Fe}_{2} \mathrm{O}_{3}$ & - & $132 \cdot 3$ & $13 \cdot 83$ \\
\hline
\end{tabular}

crystallized by annealing at $\approx 600 \mathrm{~K}$. The clustered $\mathrm{Fe}^{3+}$ ions behave ferromagnetically with high $\chi_{M}$ values (figure 1 ).

In the LT region $(15-100 \mathrm{~K})$ we observe that $\chi_{M}^{-1}$ vs. $T$ plots possess higher slopes in 
all cases, and is particularly large for $\mathrm{Fe}_{2} \mathrm{O}_{3}$-containing glasses. This is reflected in decreased $\theta_{p}$ values. Such behaviour for an amorphous antiferromagnet was predicted by Simpson (1970) in his effective field model. This model assumes the presence of isolated magnetic ions in addition to those which interact with their magnetic neighbours. As the isolated ions do not interact with their neighbours (which are structurally far away) they contribute a small paramagnetic component to the total susceptibility which obeys the Curie law. This explains the susceptibility behaviour of these glasses in the LT region. The existence of isolated ions is a natural concomitant of the glassy state. A fraction of $\mathrm{Mn}^{2+}$ and $\mathrm{Fe}^{3+}$ ions are indeed present always in magnetically isolated sites even in glasses containing high concentrations of transition metal ions (as evidenced by characteristic low field ESR resonances) (Rao and Rao 1985a). Hence the LT region is dominated by paramagnetic interactions in almost all compositions. However, the nature of the interaction can be slightly different. In the glass containing $10 \mathrm{~mol} \% \mathrm{MnO}$, the concentration of $\mathrm{Mn}^{3+}$ ions can be considerable (see later). This leads to $\mathrm{Mn}^{2+}-\mathrm{Mn}^{3+}$ interactions which can result at the least in ferromagnetic interactions. This necessarily brings down $\theta_{p}$ even for the HT region. As it was noted earlier (table 1) $\theta_{p}$ is lower for glass containing $10 \mathrm{~mol} \% \mathrm{MnO}$ as compared to glass containing $5 \mathrm{~mol} \% \mathrm{MnO}$.

In the case of $\mathrm{PbO} \cdot \mathrm{PbCl}_{2}$ glass containing $5 \mathrm{~mol} \% \mathrm{Fe}_{2} \mathrm{O}_{3}$, another essentially linear HT region with a different slope above $225 \mathrm{~K}$ was observed (figure 1). This may possibly arise from strongly antiferromagnetically coupled near-neighbour $\mathrm{Fe}^{3+}$ ions present in the glass.

It may be noted from table 1 that $\mu_{\text {eff }}$ values for glasses containing $5 \mathrm{~mol} \% \mathrm{MnO}$ obtained from the analysis of the HT region are much lower than the free ion $\mu_{\mathrm{eff}}$ value for $\mathrm{Mn}^{2+}\left(5.92 \mu_{B}\right)$ and are closer to that of $\mathrm{Mn}^{3+}\left(4.90 \mu_{B}\right)$. This value is even lower for the glass containing $10 \mathrm{~mol} \% \mathrm{MnO}$, which suggests that the fraction of $\mathrm{Mn}^{3+}$ ions increases with added manganese concentration. These observations are quite in agreement with the results of our ESR and earlier optical spectroscopy studies. The $\mu_{\text {eft }}$ values for glasses containing $5 \mathrm{~mol} \% \mathrm{Fe}_{2} \mathrm{O}_{3}$ show that most of the ions are present as $\mathrm{Fe}^{3+}$. However, it is not likely that $\mathrm{Fe}^{2+}$ ions are also produced during equilibration at melting temperature like in other lead oxide containing glasses (Burzo et al 1980). Nevertheless, $\mathrm{Fe}^{2+}$ ions may not aggregate into regions dominated by $\mathrm{Fe}^{3+}$ ions. Hence $\mathrm{Fe}^{2+}$ ions, if any, make contributions only to paramagnetic susceptibility and not to ferromagnetic type as expected in manganese containing glasses. The $\mu_{\text {eff }}$ value for the glass containing $10 \mathrm{~mol} \% \mathrm{Fe}_{2} \mathrm{O}_{3}$ is very high $\left(13.83 \mu_{B}\right)$ and may be due to the onset of dominant ferromagnetic interactions in isolated clusters.

The results discussed above point to the fact that magnetic interactions in lead oxyhalide glasses containing transition metal ions are essentially antiferromagnetic as in other covalent oxide glasses and they are different from the type of interactions in purely ionic sulphate glasses. In fact the $\theta_{p}$ value for a PbO-rich glass $\left(70 \mathrm{PbO} \cdot 25 \mathrm{PbF}_{2} \cdot 5 \mathrm{Fe}_{2} \mathrm{O}_{3}\right)$ is higher than that of $\mathrm{PbO}$-poor $(47.5 \mathrm{PbO} \cdot 47.5$ $\mathrm{PbF}_{2} \cdot 5 \mathrm{Fe}_{2} \mathrm{O}_{3}$ ) glass in the case of glasses containing $5 \mathrm{~mol} \% \mathrm{Fe}_{2} \mathrm{O}_{3}$ (glass nos. 5 and 6 in table 1). Since the magnetic interactions are most likely mediated by oxygen atoms in a super-exchange type of interaction we feel that the covalency of oxygen bonding dictates an antiferromagnetic spin orientation in these glasses. We have also noted elsewhere (Rao et al 1984a) that in $\mathrm{PbO}-\mathrm{PbF}_{2}$ glasses fluorine tends to occupy network positions with an apparently covalent $\mathrm{Pb}-\mathrm{F}$ interaction. This is also likely to play a role in the covalency effect on magnetic interactions in these glasses. 


\section{Acknowledgements}

We are thankful to Professor C N R Rao, FRS for his kind encouragement and to DST, New Delhi, for financial support. We are also thankful to the referees for helpful comments.

\section{References}

Bandyopadhyay A K, Zarzycki J, Auric P and Chappert J 1980 J. Non-Cryst. Solids 40353

Burzo E, Ardelean I and Ursu I 1980a J. Mater. Sci. 15581

Burzo E, Ursu I, Ungur D and Ardelean I 1980b Mater. Res. Bull. 151273

Burzo E, Ungur D and Ardelean I $1982 \mathrm{~J}$. Non-Cryst. Solids 50227

Egami T, Solci G A, Simpson A W, Terry A L and Wedgwood F A 1972 J. Phys. C5 L261

Friebele E J and Koon N C 1974 Solid State Commun. 141247

Hasegawa R 1971a Phys. Rev. B3 1631

Hasegawa R 1971b Phys. Status Solidi B44 613

Rao B G and Rao K J 1984 Phys. Chem. Glasses 2511

Rao B G and Rao K J 1985a Chem. Phys. (in press)

Rao B G and Rao K J 1985b J. Mater. Sci. Lett. (in press)

Rao K J and Sundar H G K 1981 Mater. Res. Bull. 161339

Rao B G, Sundar H G K and Rao K J 1984a J. Chem. Soc. Faraday Trans. I 123491

Rao K J, Wong J and Rao B G 1984b Phys. Chem. Glasses 2557

Shinkel C J and Rathenau C W 1965 in Physics of non-crystalline solids (ed.) J A Prins (Amsterdam: NorthHolland) p. 215

Simpson A W 1970 Phys. Status Solidi 40207

Simpson A W and Lucas J M 1971 J. Appl. Phys. 422181

Wilson L K, Friebele E J and Kinser D L 1973 in Amorphous magnetism (eds) H O Hooper and A M Degraff (New York: Plenum Press) p. 65 